\title{
The Epidemiology of Leukaemia in Zimbabwe: A Ten Year Retrospective Study
}

\author{
Chinembiri $\mathrm{V}^{1}$, Mandisodza $\mathrm{A}^{1 *}$, Maboreke $\mathrm{T}^{2}$, Tinago $\mathrm{W}^{3}$ and \\ Chokunonga $\mathrm{E}^{4}$ \\ ${ }^{1}$ Department of Medical Laboratory Sciences, University of Zimbabwe College of \\ Health Sciences, Zimbabwe
}

${ }^{2}$ Department of Haematology, University of Zimbabwe College of Health Sciences,

\author{
Research Article \\ Volume 1 Issue 1
}

Received Date: July 18, 2017

Published Date: August 22, 2017

DOI: $10.23880 /$ hij-16000101

Zimbabwe

${ }^{3}$ Department of Community Medicine, University of Zimbabwe College of Health Sciences, Zimbabwe

${ }^{4}$ Zimbabwe National Cancer Registry (ZNCR), Zimbabwe

*Corresponding author: Arthur Mandisodza, Department of Medical Laboratory Sciences, University of Zimbabwe College of Health Sciences, PO Box A178, Avondale, Harare, Zimbabwe, Tel: +263 4 791631, +263 772249569 ; 2397 /2295; E-mail: amandisodza@yahoo.com

\section{Abstract}

Background: Haematological malignancies are defined as primary cancers of blood cells. Leukaemia constitutes more than fifty-five percent of haematological malignancies. The epidemiology of leukaemia in Zimbabwe is currently unknown.

Aim: To investigate the incidence of leukaemia in Zimbabwe during a ten year period from 2004 to 2013.

Objective: To understand the latest epidemiology of leukaemia in the country in order to effectively manage the disease and inform policy makers.

Methods: A ten year cross sectional retrospective epidemiological study was carried out on 601 reported cases of leukaemia registered at the Zimbabwe National Cancer Registry from 1January 2004 to 31 December 2013.

Results: More males (59\%) had leukaemia than female (41\%). Children (28\%) developed leukaemia more than the adults. Chronic myelogenous leukaemia (29\%) was the most common type of leukaemia, followed by acute myeloid leukaemia (24\%), acute lymphoblastic leukaemia (18\%), unclassified (17\%) and chronic lymphocytic leukaemia (12\%). Harare had the highest and Matebeleland South the lowest reported cases of leukaemia. Unemployed adults had the highest incidence followed by children.

Conclusion: Zimbabwe has an increasing burden of the leukaemia compared to developed countries. A high proportion of leukaemia was not classified, making it difficult to come up with reliable subtypes of the disease. More men and children were affected than women and the elderly respectively. The distribution of types of leukaemia was consistent with literature information. Unemployed people appeared to have a higher risk for developing leukaemia in Zimbabwe.

Keywords: Cancer; Haematological malignancies; Leukaemia; Epidemiology; Diagnosis 


\section{Introduction}

Globally, cancer is now becoming a leading cause of morbidity and mortality. There are several types of cancer. Lung, breast, cervical, bladder, prostate and haematological malignancies are the major types. Close to half of the world population will develop some cancer at some point in their lifetime. According to global cancer statistics, cancer burden has continued to increase in developing countries. This has been associated with aging population, adoption of Western lifestyles such as smoking, inactivity and diet, exposure to various cancer causing agents such as ionizing radiation, viral infections, chemicals, chemotherapeutic drugs and hair dyes. Some cancers are familial. In Sub Saharan Africa, cancer affects 1 in 1500 people, but it has not been given the attention it deserves due to preoccupation with communicable diseases [1-4].

Haematological malignancies are defined as primary cancers of blood cells. They account for nearly eight per cent and ten percent of the cancer burden in the world and Sub Saharan Africa respectively. They consist mainly of lymphoma, leukaemia and myeloma. These are now the major causes of death in Sub Saharan Africa. The situation has been worsened by the emergence of cancer causing viruses such as human immune deficiency virus (HIV), Epstein-Barr virus (EBV), cytomegalovirus (CMV) and Herpes virus (HV). Malaria infection is now being linked to haematological malignancies because the Plasmodium falciparum species has been found to have a capacity to stimulate the expansion of $\mathrm{B}$ - and inhibition of T- lymphocytes resulting in $B$ cell malignancies, either in the form of leukaemia or lymphoma [3-5]. According to a previous study, leukaemia constitutes more than fifty-five percent of haematological malignancies. Leukaemia is classified into acute or chronic, which can be classified further into myeloid and lymphoid subtypes using morphological, cytochemical, immunologic, cytogenetic and molecular techniques $[3,6,7]$. Based on the above, leukaemia can be categorized as acute myeloid leukaemia (AML), acute lymphoblastic leukaemia (ALL), chronic myelogenous leukaemia (CML) and chronic lymphocytic leukaemia (CLL). For appropriate treatment, these can be subtyped further [7,8]. Immunological, cytogenetic and molecular technologies have allowed classification of acute leukaemia into more subtypes, thereby improving the diagnosis and treatment of the disease.

While the epidemiology of leukaemia has been done in some other parts of Sub Saharan Africa, information on leukaemia in Zimbabwe was gathered more than twenty years ago and some of it only involved acute leukaemia [8-10]. The emergence of cancer causing communicable diseases, such HIV/AIDS, has changed the pattern of the epidemiology of leukaemia [11]. The absence of consultant haematologists in the country for past fifteen years has also made it difficult to deal with challenges associated with haematological diseases. Since data on the epidemiology was gathered more than fifteen years ago and was mainly on acute leukaemia, there was an urgent need to revise the studies $[9,10]$. This has also been necessitated by the increased burden of the disease and environmental factors which are associated with risks of cancer development. This study was carried out to determine the current epidemiology of leukaemia in Zimbabwe.

\section{Material and Methods}

A retrospective cross sectional study was carried out on 601 reported cases of leukaemia registered at the Zimbabwe National Cancer Registry (ZNCR) for a ten year period from 1January 2004 to 31 December 2013. The calculated minimum sample size for the study was 384. To avoid missing data due to early death in health institutions, NCRZ traced back the records and a new register was created. Demographic information was obtained from NCRZ. Codes were used and supplied by NCRZ to maintain confidentiality and minimize duplications.

The inclusion criteria were all male and female patients of all ages who were diagnosed with leukaemia in Zimbabwe in a 10 year period $(1 / 1 / 2004$ to $31 / 12 / 2013$ ) as per NCRZ records. The exclusion criteria were patients who were diagnosed with leukaemia in Zimbabwe but were not residing in the country during the study period, patients diagnosed with leukaemia in Zimbabwe before 1January 2004 but were registered during the period of study and patients diagnosed with leukaemia from outside the country and referred to Zimbabwean health institutions for management.

Permission to carry out the study and access to data were granted by the Joint Research Ethics Committee of the College of Health Sciences and Parirenyatwa Group of Hospitals (JREC 315/15) and NCRZ respectively.

\section{Results}

Records available from the ZNCR on all cancer cases indicated that 601(1.4\%) were diagnosed with leukaemia in Zimbabwe. There appeared to be a gradual decrease in leukaemia from 2004 to 2008 and a steady increase from 2009 to 2013 (Figure 1). 


\section{Haematology International Journal}

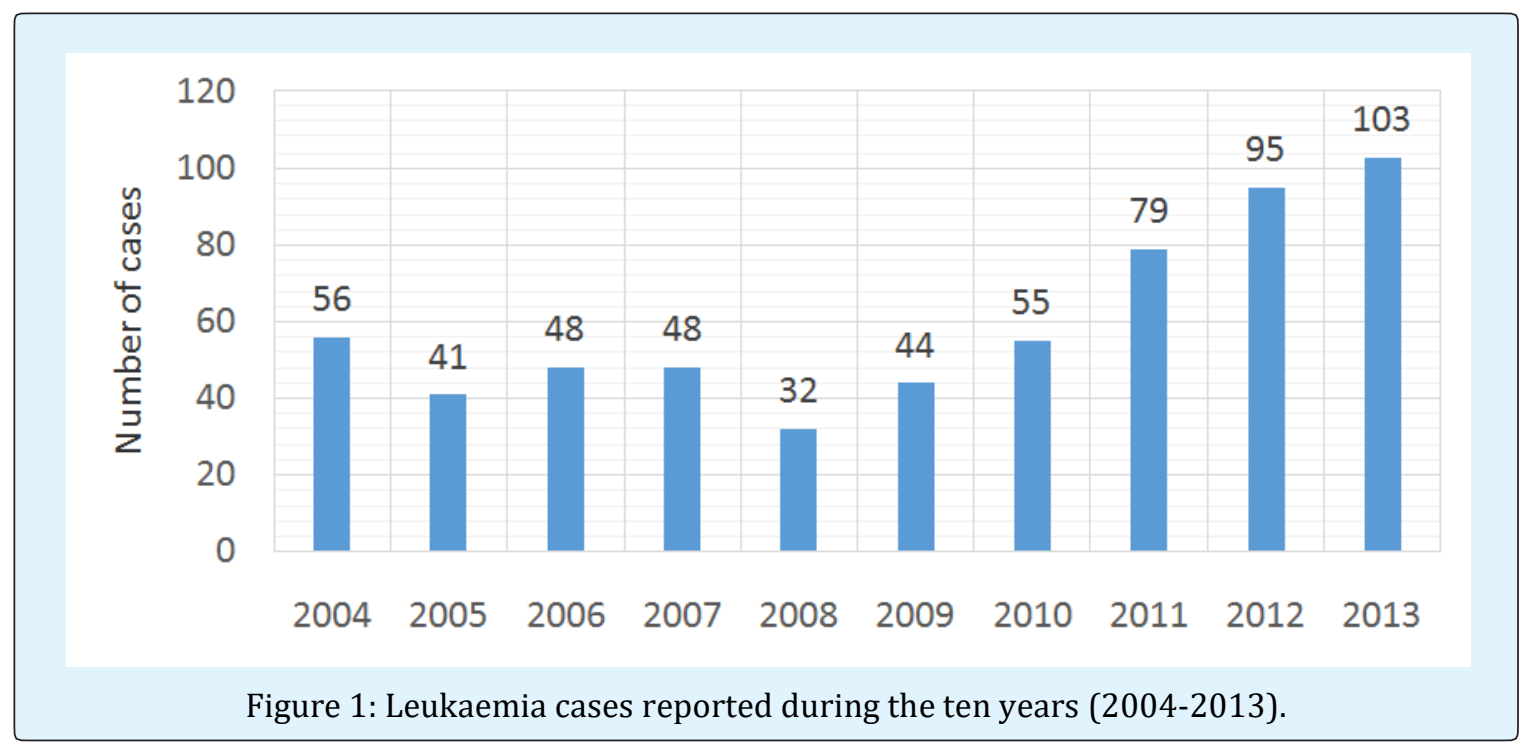

Demographically, 353 (59\%) males and 248 (41\%\} females had leukaemia. Children $(<14$ years $)$ and the elderly ( $>75$ years) were the most and least affected age groups respectively (Figure 2). Harare and Bulawayo are Zimbabwe's first and second largest urban areas respectively. The two cities had the highest incidence of leukaemia of $290(48.3 \%)$ and $44(7.3 \%)$ respectively. Smaller cities and rural areas had a combined 267 $(44.4 \%)$ incidence of leukaemia.

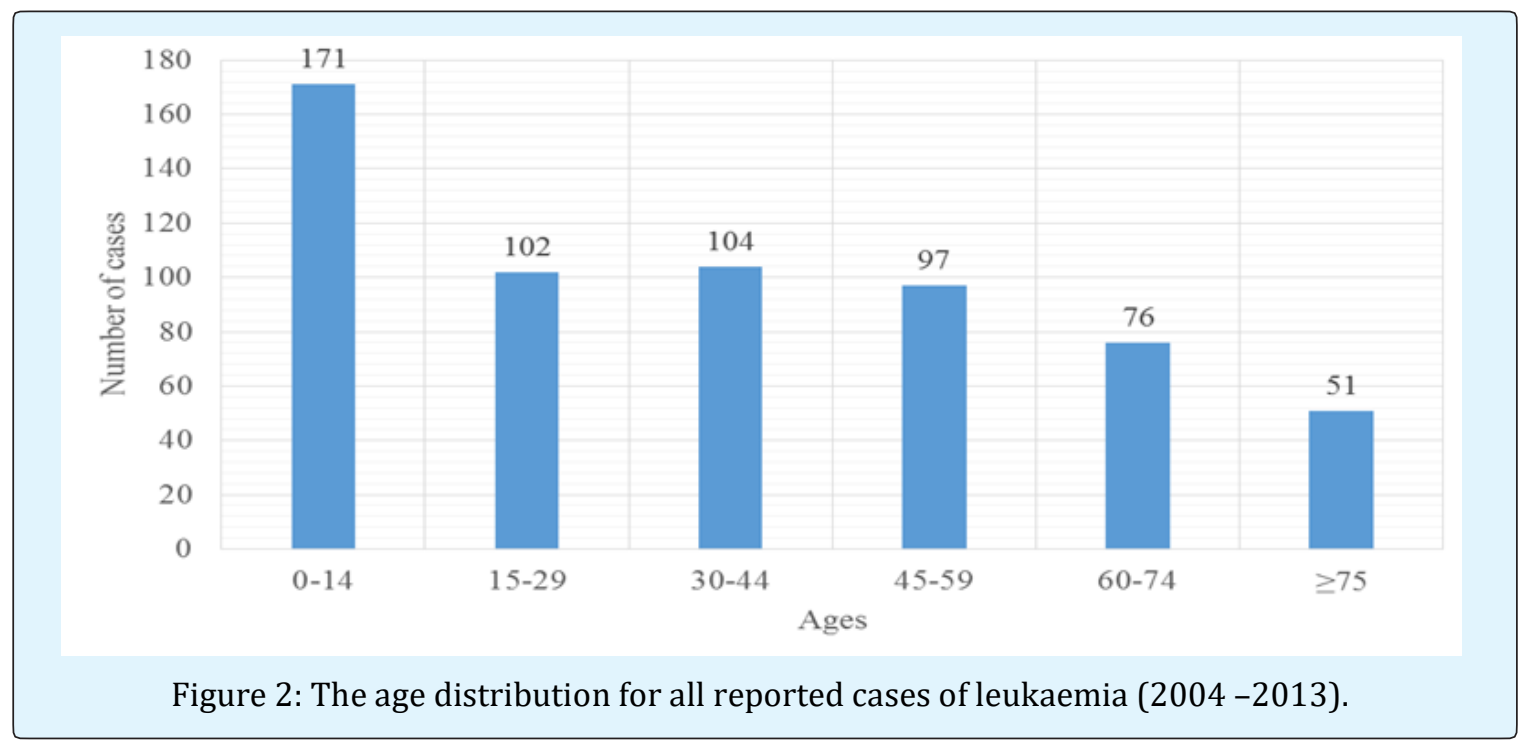

The incidence of leukaemia was in the following decreasing order: chronic myelogenous leukaemia 173 (29\%), acute myeloid leukaemia147 (24\%), acute lymphoblastic leukaemia 106 (18\%), unclassified leukaemia $103 \quad(17 \%)$ and chronic lymphocytic leukaemia 72 (12\%).

ALL was predominantly found in children, AML in children and young adults, CML in the middle aged, CLL in the elderly and unclassified leukaemia in children and young adults (Table 1). Harare and Matebeleland South had the highest and lowest reported cases of leukaemia respectively (Table 2). The occupational distribution of leukaemia showed the highest incidence in unemployed adults followed by children (Table 3).

\begin{tabular}{|c|c|c|c|c|c|c|}
\hline Age & $\begin{array}{c}\text { ALL } \\
\text { n (\%) }\end{array}$ & $\begin{array}{c}\text { AML } \\
\text { n (\%) }\end{array}$ & $\begin{array}{c}\text { CML } \\
\mathbf{n}(\%)\end{array}$ & $\begin{array}{c}\text { CLL } \\
\text { n (\%) }\end{array}$ & $\begin{array}{c}\text { Unclassified } \\
\text { n (\%) }\end{array}$ & $\begin{array}{c}\text { Total } \\
\text { n (\%) }\end{array}$ \\
\hline $0-14$ & $76(44.4)$ & $52(30)$ & $10(5.9)$ & $2(1)$ & $31(18)$ & $171(100)$ \\
\hline $15-29$ & $16(15.7)$ & $29(28.4)$ & $28(27.5)$ & $4(3.9)$ & $25(24.5)$ & $102(100)$ \\
\hline $30-44$ & $4(3.8)$ & $22(21.2)$ & $57(54.8)$ & $3(2.9)$ & $18(17.3)$ & $104(100)$ \\
\hline
\end{tabular}




\begin{tabular}{|c|c|c|c|c|c|c|}
\hline $45-59$ & $3(3.1)$ & $18(18.6)$ & $47(48.5)$ & $18(18.5)$ & $11(11.3)$ & $97(100)$ \\
\hline $60-74$ & $0(0)$ & $13(17.1)$ & $21(27.6)$ & $28(36.8)$ & $14(18.5)$ & $76(100)$ \\
\hline$>75$ & $7(13.7)$ & $13(25.5)$ & $10(19.6)$ & $17(33.4)$ & $4(7.8)$ & $51(100)$ \\
\hline
\end{tabular}

Table 1: Age group (years) distribution of leukaemia sub types.

\begin{tabular}{|c|c|c|}
\hline Province & Leukaemia Cases & (\%) \\
\hline Bulawayo & 44 & 7.3 \\
\hline Harare & 290 & 48.3 \\
\hline Manicaland & 17 & 2.8 \\
\hline Mashonaland Central & 22 & 3.7 \\
\hline Mashonaland East & 84 & 13.9 \\
\hline Mashonaland West & 43 & 7.1 \\
\hline Masvingo & 26 & 4.3 \\
\hline Midlands & 30 & 5 \\
\hline Matebeleland North & 16 & 2.7 \\
\hline Matebeleland South & 7 & 1.2 \\
\hline Unspecified & 22 & 3.7 \\
\hline TOTAL & 601 & 100 \\
\hline
\end{tabular}

Table 2: Geographical distribution of Leukaemia in Zimbabwe.

\begin{tabular}{|c|c|c|}
\hline Occupation & $\begin{array}{c}\text { Numbers of } \\
\text { cases }\end{array}$ & $\begin{array}{c}\text { Percentage } \\
\text { (\%) }\end{array}$ \\
\hline Office workers & 36 & 6 \\
\hline Industry workers & 24 & 4 \\
\hline Unemployed adults & 214 & 35.6 \\
\hline Teachers and students & 65 & 10.8 \\
\hline Security & 11 & 1.8 \\
\hline Health workers & 6 & 1 \\
\hline Business people & 11 & 1.8 \\
\hline House keeping & 72 & 12 \\
\hline Pensioner & 25 & 4.2 \\
\hline Children & 137 & 22.8 \\
\hline Total & $\mathbf{6 0 1}$ & $\mathbf{1 0 0}$ \\
\hline
\end{tabular}

Table 3: Occupational Distribution of Leukaemia in Zimbabwe.

\section{Discussion}

More males were registered with leukaemia than females. The possible explanation may be that males are involved in occupations that may expose them to carcinogenic substances such as ionizing radiation, electromagnetic energy or industrial and agricultural chemicals $[1,3,11,12]$. It has also been found that an abnormal mutation of the KDM6A tumor suppression gene on chromosome $\mathrm{X}$ in males could make them more susceptible to cancer than females [12].

The gradual decrease in leukaemia during the 2004 to 2008 period could have been due to the deterioration

in socioeconomic conditions that prevailed. The trend is more likely to reflect Cancer Registry Data capturing activity than a change in leukaemia incidence. From 2004 to 2008, there was progressive economic downturn with consequent deterioration in registry data capturing. Similarly from 2009 to 2013, the apparent increase in incidence of leukaemia is most likely due to improved data collection as a result of economic upturn. A similar trend in cancer epidemiology from 2005-2014 was reported by the ZNCR in their most recent report [13]. But, it can also be hypothesized that the improvement in the socioeconomic conditions could have allowed patients to afford treatment in hospitals making it possible to diagnose various diseases including haematological malignancies.

Although global leukaemia epidemiology showed an increase in leukaemia with age, our study indicated that children were the most affected by the disease than adults. This could be associated with low life expectance in the Zimbabwe, which currently stands at 58/62 for males/females, according to the latest WHO statistics [13]. The elderly population has significantly declined thereby affecting the age distribution of leukaemia. Studies have indicated ethnic and geographical variations to be also responsible for this converse relationship. Other studies indicated a significant decline in adult cancer burden and increase in childhood cancer. The exact reason is not fully understood. However, it is thought children are now being exposed to genetic and environmental risk factors. It has been found that children of fathers who smoke when the mother is pregnant are likely to develop leukaemia. Women who use household pesticides and chemicals are likely to have children who develop leukaemia. The adult rates have declined due to intensive treatment methods now being used by haematologists $[14,15]$. Certain genetic diseases such as Down's syndrome, Bloom's syndrome, Klinefelter's syndrome, Wiskott-Aldrich syndrome, Li-Fraumeni syndrome, Aplastic anaemia and Fanconi anaemia- also known as preleukaemic conditions, tend to predispose children to leukaemia [16-18].

Zimbabwe lies within malaria endemic regions of the world. The contribution of malaria as a causative agent of haematological malignancies cannot be ruled out as P.falciparum has been known to induce polyclonal Bcell expansion and impair T-cell immune responses [5]. 
Chronic myelogenous leukaemia (CML) was the most common leukaemia. The finding agreed well with a previous study in Rhodesia although CML was much higher in that study [10]. The global incidence of CML is less than twenty percent. The converse relationship may have been also due to ethnic and geographical variations and levels of poverty [19]. The high level of unclassified leukaemia was not acceptable because this was an indication poor diagnosis. The study period was associated with severe shortage of skilled personnel for haematology.

With adequate skilled personnel and use of currently available haematology techniques, leukaemia would be more accurately diagnosed and identified for appropriate management $[16,17]$. ALL was high in children and AML was high in both children and young adults. The converse relationship with studies in developed countries also suggested an ethnic variation [20]. Chronic lymphocytic leukaemia had the lowest incidence. This could also be associated with ethnic variation. The pattern of leukaemia could have been affected by the high incidence of unclassified leukaemia. With proper and reliable diagnosis, unclassified would have been allocated to appropriate main subtypes, changing the epidemiological pattern of leukaemia altogether.

The distribution of leukaemia according to age groups was consistent with what is normally found in literature which shows that ALL, AML, CML and CLL are predominantly found in children, children and young adults, middle age and the elderly respectively $[3,16,17]$. Again, with proper diagnosis, the unclassified leukaemia will fit into any of these major types, thereby altering the incidence pattern.

The large disparity between Harare and Matebeleland South is primarily socioeconomic. Harare has the highest concentration of healthcare facilities, people and skilled manpower. The standard of living is relatively higher and people have easy access to good healthcare facilities for medical attention. Matebeleland South, being largely rural, has no access to good health facilities for proper disease management resulting in missed diagnosis of leukaemia. It is also important to note that Harare, as a major city, has one of the largest concentrations of industries. Therefore more people are exposed to hazardous industrial materials. Health workers were the least affected. This could be attributed to basic knowledge about diseases in general.

Harare and Bulawayo, being Zimbabwe's two largest urban areas, have the highest concentration of health facilities, allowing urban dwellers easy access to affordable medical services than their rural counterparts. This could be one reason why the study showed high incidence of leukaemia. The other reason could be a high rate of exposure to hazardous materials associated with industrial waste in urban settings.

Zimbabwe has a high unemployment rate. Although the high incidence of leukaemia with unemployment is not clearly understood, it is hypothesized that unemployed people are exposed to carcinogenic materials in their informal sector activities. The absence of safety regulations in this sector exposes people to potential carcinogens. The country is endowed with minerals and many unemployed people are now engaging in artisanal mining without adequate protection, thereby exposing themselves to dangerous chemicals such as mercury and cyanide. Some are involved in chromium, lithium and uranium mining exposing them to ionizing radiation. A study done in the Democratic Republic of Congo (DRC) has shown that artisanal miners were highly exposed to radiation by cobalt, uranium and cadmium. The miners also caused radioactive pollution of rivers, thereby endangering many lives in the Katanga region. The artisanal mining sites have attracted women who engaged in prostitution resulting in elevated HIV, EBV and CMV infections which are known leukaemia risk factors [21,22].

\section{Conclusion}

While there has been a decline in leukaemia in the world our study has shown Zimbabwe to have an increasing burden of the disease. A high percentage of leukaemias were not classified, making it difficult to come up with a reliable classification of leukaemia. Men were affected more than women. Children were the most affected with steady decline with age. Conversely, developed countries have leukaemia that appeared to increase with age. The distribution of different types of leukaemia was the same as in developed countries. Unemployed people had the highest risk for developing leukaemia.

\section{Limitations}

a. Cancer Registry Data only reflected those cases that reached hospital leading to underrepresentation.

b. Lack of haematology expertise and use of obsolete techniques in haematology presented a challenge on accurate diagnosis of leukaemia and compilation of reliable data.

c. This study was carried out during time of negative socioeconomic conditions. Many patients with leukaemia would not afford healthcare and were not represented in registry data. 
d. Many cases with acute leukaemia would die before reaching hospital leading to underrepresentation of acute leukaemia in the registry data.

\section{Recommendations}

a. A new comprehensive 5 or 10 year prospective study should be done considering the current improvement in haematology expertise.

b. Diagnostic techniques such as morphology, cytochemistry, immunophenotyping and molecular analysis should be used for accurate diagnosis of leukaemia.

c. NCRZ data capturing system needs to be improved in order to be able to capture all cases of leukaemia.

d. Now that there a few haematologists available in the country, there is need to co-opt one or two of them to the Zimbabwe National Cancer Registry Advisory Committee. This will help in the compilation of more accurate data on haematological malignancies.

e. A follow up study may be required to compare the burden of leukaemia in rural and urban settings.

\section{References}

1. INCTR Team (2016) Cancer in Developing Countries. International Network for Cancer Treatment and Research 1-7.

2. Parkin DM, Sitas F, Chirenje M, Stein L, Abratt R, et al. (2008) Part 1: Cancer in Indigenous Africansburden, distribution and trends. The Lancet Oncology 9(7): 683-692.

3. Hoffbrand AV, PAH Moss (2011) The Etiology and genetics of Haematological Malignancies: Essential Haematology $6^{\text {th }}($ Edn), Wiley-Blackwell, pp: 151287.

4. Jemal A, Bray F, Center MM, Ferlay J, Ward E, et al. (2011) Global Cancer Statistics. CA Cancer J Clin 61 (2): 69-90.

5. Gopal S, Wood WA, Lee SJ, Shea TC, Naresh KN, et al. (2012) Meeting the challenges of haematological malignancies in Sub Saharan Africa. Blood 119(22): 5078-5087.

6. Babatunde A, Amiwero C, Olatunji P, Durotoye I (2008) Pattern of haematological malignancies in Ilorin, Nigeria. Internet J Haematol 5(2): 1-9.

7. Omoti CE, Imiere EO (2006) Trends in the Pattern of Leukaemia incidence in a Tertiary Health Center in Nigeria. Journal of Medicine and Biomedical Research 5(2): 44-49.
8. Fleming A (1993) Leukaemia in Africa. Leukemia 2: 138-141.

9. Paul B, Mukiibi JM, Mandisodza A, Levi L, Nkrumah FK (1992) A three-year prospective study of 137 cases of acute leukaemia in Zimbabwe. Cent Afr J Med 38(3): 95-99.

10. Lowe RF (1974) The Incidence of Leukaemia in the Rhodesian Africans. Cent Afr J Med 20(4): 80-84.

11. Driscoll T, Steenland K, Prüss-Üstün A, Nelson DI, Leigh J (2004) Occupational carcinogens: Assessing the environmental burden of disease at national and local levels. World Health Organization (Environmental Burden of Disease Series, No. 6: 156.

12. Jewett C (2012) Adult cancer cases drop, rates go up among children. California Watch: Health and Welfare Daily Report 1-2.

13. Chokunonga E, Borok MZ, Chirenje ZM, Nyakabau AM, Makunike-Mutasa R, et al. (2016) Cancer incidence in Harare: A Triennial Report 2010-2012 23-41.

14. Dunford A, Weinstock DM, Savova V, Schumacher SE, Cleary JP, et al. (2016) Tumor-suppressor genes that escape from $\mathrm{X}$-inactivation contribute to cancer sex bias. Nat Genet 49(1): 10-16.

15. Zahm SH, Ward MH (1998) Pesticides and Childhood Cancer. Environ Health Perspect 106 (3): 893-908.

16. Hoffbrand AV, Pettit JE (1993) Haematological Malignancies. Essential Haematology $3^{\text {rd }}$ (Edn), Blackwell Scientific Publications pp: 186-244.

17. Hall R, Malia RB (1986) The Proliferation Disorders: techniques in the investigation of proliferation disorders. Medical Laboratory Haematology 2nd (Edn.), Butterworth \& Co. Publications pp: 392-454.

18. Cancer Treatment Centers of America (CTCA) (2015) Team Leukaemia risk factors: gender, age, others. CTCA: $1-2$.

19. Lee JP, Birnstein E, Masiello D, Yang D, Yang AS (2009) Gender and ethnic differences in chronic myelogenous leukaemia prognosis and treatment response: a single-institution retrospective study. J Haematol Oncol 2: 30. 
20. Yamamoto JF, Goodman MT (2008) Patterns of leukaemia incidence in the United States by subtype and demographic characteristics, 1997-2002. Cancer Causes and Control 19(4): 379-390.

21. Tsurukawa N, Prakash S, Manhart A (2011) Social impact of artisanal cobalt mining in Katanga,
Democratic Republic of Congo. Institute of Applied Ecology 39-40.

22. WHO Team (2012) Zimbabwe: World Health Organization Statistical profile. Global Health Observatory. 